\title{
CULTURAL ANTECEDENTS TO THE NORMATIVE, AFFECTIVE, AND COGNITIVE EFFECTS OF DOMESTIC VERSUS FOREIGN PURCHASE BEHAVIOR
}

\author{
Suzanne L. CONNER ${ }^{1}$, James REARDON ${ }^{2}$, Chip MILLER ${ }^{3}$, \\ Laura SALCIUVIENE ${ }^{4}$, Vilte AURUSKEVICIENE ${ }^{5}$ \\ ${ }^{1}$ Georgia Southwestern State University, 800 GSW State University Dr, \\ Americus, GA, 31709, USA \\ ${ }^{2}$ Monfort College of Business, University of Northern Colorado, 800 17th Street, \\ Greeley, CO, 80639, USA \\ ${ }^{3}$ College of Business and Public Administration, Drake University, \\ 2507 University Avenue, Des Moines, IA 50311, USA \\ ${ }^{4}$ Lancaster University Management School, Lancaster University, \\ Charles Carter building, Lancaster, LA1 4YX, United Kingdom \\ ${ }^{5}$ ISM University of Management and Economics, Arkliu g. 18, LT-01305, Vilnius, Lithuania \\ E-mails: ${ }^{1}$ suzanne.conner@gsw.edu; ${ }^{2}$ james.reardon@unco.edu; ${ }^{3}$ chip.miller@drake.edu; \\ ${ }^{4}$ l.salciuviene@lancaster.ac.uk; ${ }^{5}$ vilaur@ism.lt (corresponding author) \\ Received 30 December 2015; accepted 02 August 2016

\begin{abstract}
The paper aims to investigate simultaneous and independent effects of cognitive, affective, and normative (CAN) decision mechanisms and cultural elements on consumer purchase behavior of foreign and domestic products. The study uses a survey to collect data from 5086 respondents across 19 nations. The findings suggest that CAN factors independently affect purchase decisions for domestic, but not always foreign goods. Collectivism and uncertainty avoidance directly and differentially affect the CAN mechanisms. By explaining the effects of CAN and cultural elements on foreign and domestic purchase behaviour and offering product positioning strategies to internationally operating business managers the study provides important research and practical implications. The originality and value of this research lies in the theoretically proposed and empirically tested model, which incorporates consumer ethnocentrism, quality importance, national identification, cultural antecedents (collectivism and uncertainty avoidance) and domestic/ foreign product purchase behaviour.
\end{abstract}

Keywords: ethnocentrism, uncertainty avoidance, collectivism, quality, national identification, domestic purchase, foreign purchases.

JEL Classification: M31.

\section{Introduction}

Despite fifty years' study of country-of-origin (COO) effects (see Chen et al. 2014; Al-Aali et al. 2015; Arora et al. 2016), findings are contradictory, empirically incongruous and theoretically weak. While consensus has been reached regarding the CAN 
elements (see Koubaa, Methamem 2015), few empirical studies simultaneously apply these facets of consumer-preference formation; even then they "fail to sufficiently implement this distinction (of country image) at the operationalization stage" (see Roth, Diamantopoulos 2009: 736). Also, while implied that foreign purchase behaviors (FPB) and domestic purchase behaviors (DPB) are culture bound, there is limited integration of cultural elements into $\mathrm{COO}$ and/or ethnocentrism models. Finally, little research has focused on actual purchase behaviors (see Josiassen, Harzing 2008). This study answers two research questions: which relative effects - normative, affective or cognitive - are greater for foreign and domestic product purchases and how do these factors influence actual purchase behaviour rather than intent to purchase? The latter is particularly important because it is well established that intent is not necessarily a good measure of actual later behaviour.

The purpose of this research is twofold: first, to develop a more robust model incorporating CAN and cultural elements into studies of consumer domestic and foreign product choices. Second, study actual FPB and DPB instead of intent, increasing the validity of the outcome measures. Thus, the contribution of this study manifests itself in developing and authenticating an extended ethnocentrism model that incorporates Consumer Ethnocentrism (CET), Quality Importance (QI), National Identification (NatID), and pertinent cultural antecedents (Collectivism and Uncertainty Avoidance) and simultaneously and independently assessing the effects on FPB and DPB.

\section{Conceptual framework}

A substantial body of literature addresses $\mathrm{COO}$ effects and domestic/foreign product preference (see Shankarmahesh 2006), yet little focuses on actual purchase behavior. Based on Verlegh and Steenkamp's (1999), Vida and Reardon (2008) have demonstrated that models of CET can be used to partial out relative impact of CAN influences on DPB. Based on these recent models, we expand the scope of inquiry to FPB and DPB. Verlegh and Steenkamp (1999) distinguish COO effects among CAN mechanisms and suggest future inquiry should account for all three mechanisms. Roth and Diamantopolous (2009) conclude that conations of COO effects should be theoretically modelled as a function of cognition, affect and country related norms.

When affect and cognition are consistent, both contribute strongly and equally to the evaluation of an object. However, when beliefs (cognitive) and feelings (affect) are of opposite valence or consumers are ambivalent, feelings tend to predominate (see Ajzen 2001). Klein et al. (2006) suggest trade-offs between CAN mechanisms. The current study assesses the effects of QI (cognitive), NatID (affective) and CET (normative) on FPB and DPB (conative).

Cultural variables are occasionally seen in $\mathrm{COO}$ models and recently were grouped with social/psychological factors as direct antecedents to CET (Lee et al. 2007). Although criticized and complimented, Hofstede's UA and COL are widely used factors in crosscultural consumer behavior (Soares et al. 2007). COL explains a significant share of 
cross-national variance in consumer behavior research (Lee, Kacen 2008). High UA, "the extent to which the members of a culture feel threatened by uncertain or unknown situations" (Hofstede 2001: 161), has been shown to affect purchase decisions (Broderick 2007).

\section{Model development and hypotheses}

In the current study, normative beliefs are represented by CET where the consumer wishes to protect their country (Shimp, Sharma 1987). Extant research demonstrates that CET negatively influences consumer attitudes towards foreign goods (Balabanis, Diamantopoulos 2004; Guo 2013; Mockaitis et al. 2013). The literature suggests that consumers with high CET will purchase domestic products (Tsai et al. 2013), regardless of how they compare to foreign counterparts (Verlegh 2007); one can like foreign products yet not buy them since purchasing domestic products aligns with one's normative mechanisms. Thus:

H1a: The absolute relative effect size of ethnocentrism will be great on DPB than FPB.

Unlike the differential impact of CET on FPB and DPB, there has been no supposition in the literature about the relative effects of cognitive or affective mechanisms. Quality importance (QI) is an efficient cognitive mechanism measure for three reasons. First, the importance of and sensitivity to quality has a significant impact on the amount of cognitive processing prior to decision (Bertini et al. 2012). Cognition produces product and choice evaluations, is a more holistic construct than specific product-quality evaluations and both the evaluation of quality and its importance combine to form intent based on cognitive processing (Fishbein, Middlestadt 1995). Second, according to the Elaboration Likelihood Model, increased motivation leads to higher involvement and greater processing of information (Petty et al. 1983). Thus, increasing QI implies higher involvement with the products, leading to purchase decisions that require processing through the central processing (cognitive) route. Finally, information search is a direct antecedent to decision, whereas product quality (Ahmed, d'Astous 2008) is a function of quality sensitivity (Bertini et al. 2012). Therefore the cognitive aspect, an individual difference, will have a greater impact on the preference for foreign goods. As QI increases, one has more alternatives in a consideration set, implying more foreign goods will be reflected upon. The only instance where higher QI would translate into higher domestic purchases would be when the home country is clearly the best producer of all goods. Hence:

H1b: Quality importance will have a greater relative effect on FPB than DPB.

Affect refers to one's feelings and affective choices are largely emotional responses to the product (Petty et al. 1983). In this study, affect plays a significant role in the formation of NatID. According to Druckman (1994: 63), nations “....achieve personal relevance for individuals when they become sentimentally attached to the homeland (affectively involved), motivated to help their country (goal-oriented), and gain a sense of identity and self-esteem through their national identification". While NatID is a nor- 
mative component of CET, it may have different effects than CET since CET includes a bias towards outgroups (see Balabanis et al. 2001).

We expect a positive effect of NatID on DPB and a negative effect on FPB. In absolute terms the effect on DPB would be of higher magnitude. However, relative effects as directionality is removed are harder to specify. On one hand, we would expect H1a to apply here; love for one's country and NatID should drive high effects on DPB, but not necessarily on FPB (Nes et al. 2014). However, some literature on animosity models suggests a potential opposite effect; consumers might refuse to buy products from a country with which they associate high negative affect (Nakos, Hajidimitriou 2007). Given that the animosity model is less universal than NatID effects, we test the second. Thus:

H1c: National ID will have a greater relative effect on DPB than FPB.

Culture affects how individuals think and behave, and has been established as an antecedent to consumer attitudes and behaviors. The ethnocentrism model has been empirically recognized as culturally dependent. Suh and Kwon (2002) demonstrate that ethnocentrism is an important factor in assessing foreign quality and FPB, yet varies based on the cultural context. This study focuses on Hofstede's (2001) dimensions uncertainty avoidance (UA) and collectivism (COL).

COL refers to "a society in which people from....are integrated into strong, cohesive in-groups" (Hofstede 2001: 225). Consequently, collectivists have an emotional dependence on the group, value a sense of belonging, and respect traditions and social norms (Triandis 1995); they consult their reference group (Sharma et al. 1995) and rely more on word-of-mouth information (Chen 2013) when making purchases.

COL has been a cultural antecedent in COO evaluations (Ahmed, d'Astous 2008) shown to explain COO perceptions (Suh, Kwon 2002). However, research has not always shown consistent results within and among the CAN influences regarding COL. Franke and Nadler (2008) examine effects of COL on normative elements and suggest there are no differences between collectivist and individualist attitudes. Conversely, Mourali et al. (2005) observe differences and conclude collectivists are more susceptible to normative influences than individualists. These differences "are partly driven by cultural differences in individualistic orientation" (Mourali et al. 2005: 164). Similarly, Lee and Kacen (2008) find individualists less affected by normative (social) influences than collectivists. Cleveland and Laroche (2007) incorporate COL with other cultural dimensions to predict effects (indirectly via acculturation to the global consumer culture and ethnic identity) on CET leading to consumption behavior. Sharma et al. (1995: 29) suggest "Collectivistic persons...evince strong CET because they tend to consider the effect of their behavior on society....and are more susceptible to social influence against imports...". Therefore:

H2a: Collectivism has a positive effect on ethnocentrism (CET).

Ahmed and d'Astous (2007) propose that cognitive elements (e.g., quality, originality or performance) are affected by nationality and other variables as they shape COO per- 
ceptions. Literature on COO is unclear and situation specific. Verlegh (2007) refers to instances where cognitive factors overcome the influence of group pressure or NatID. Conversely, Johansson (2009) suggests consumers might be more affected by group pressure than by cognitive evaluations of product choices. Because of limited evidence to suggest a specific direction of the effect of $\mathrm{COL}$ on cognitive mechanisms, we must rely on logic. Overall, collectivists use more holistic thinking and rely on normative factors to make decisions. Individualists tend to rely more on "pulling-apart, distinguishing-and-separating" cognitive strategies (Oyserman, Lee 2008) that involve intense processing at the individual level. Individualists, relying less on normative mechanisms seem to have a more cognitively challenging task. Therefore:

H2b: Collectivism has a negative effect on cognitive mechanisms (QI).

There is scant business research to suggest specific relationships between COL and affective decision processes. However, Oyserman and Lee's (2008) meta-analysis of sociocultural research found that individualists tend to associate well-being with happiness and self-fulfillment (affective elements), whereas collectivists tend to rely both on social/relational identities (normative influences) as well as self-focused affective issues. The affective influence here is NatID which evokes emotions, love and concern for country (Vida, Reardon 2008; Verlegh, Steenkamp 1999). Because NatID also contains a sense of group association, we propose a strong reliance on affective motivations for decisions. Thus:

H2c: Collectivism has a positive effect on national identity perceptions.

It is interesting to determine the relative effects of COL on CAN decisions. While collectivism will likely influence the cognitive process $(\mathrm{H} 2 \mathrm{~b})$, the direction and magnitude of its effect on QI is less clear. We suggest collectivism would influence the normative and affective elements more than the cognitive. Also, most literature suggests that collectivism has a more pronounced impact on normative mechanisms than on affective (Lee, Kacen 2008; Mourali et al. 2005). Therefore:

H3a: Collectivism has a greater effect on affective mechanisms of consumer choice than on cognitive factors $(\mathrm{H} 2 \mathrm{c}>\mathrm{H} 2 \mathrm{~b})$.

H3b: Collectivism has a greater effect on normative factors of consumer choice than on affective factors $(\mathrm{H} 2 \mathrm{a}>\mathrm{H} 2 \mathrm{c})$.

Hofstede (2001: 161) defines UA as "the extent to which the members of a culture feel threatened by uncertain or unknown situations". Yoo and Donthu (2005) found high UA people less likely than low UA to adopt imported products. However, there is a lack of research on the overall effect of UA on FPB and DPB and the mechanisms leading to these choices. To reduce uncertainty, high UA consumers are expected to expend great time and effort on purchase decisions (Dacin, Smith 1994). Logically, higher UA countries would tend to use all mechanisms to reduce uncertainty. Conversely, low UA consumers may be prone to making impulse decisions that lack cognitive processes. Thus:

H4a: UA has a positive effect on quality importance. 
Normative behavior is driven by the perceived prescriptions of important others. Those with high UA should look to others in their group for cues on suitable behavior. Following the leader avoids anxiety from making independent decisions and preserves their comfort by maintaining structured relationships (de Matos et al. 2011). High UA individuals prefer stability (Lam et al. 2012) and are likely to seek well-known products owned by many people. Therefore:

H4b: UA has a positive effect on ethnocentrism (CET).

Purchase risk can be rational or emotional. Thus, the logic for high UA consumers using affective mechanisms for choice decisions broadly parallels that of cognitive mechanisms. Generating positive feelings about the chosen product because it corresponds to one's NatID reduces potential anxiety about the purchase. High UA consumers are more likely than low UA consumers to rely on emotional and affective cues - such as personal attachment to their nation - when making product choices. Hence:

H4c: UA has a positive effect on national identity of product choice.

Overall, while high UA consumers will utilize all mechanisms more than low UA consumers, the literature suggests no primacy of mechanisms. Therefore, post hoc analysis is conducted without reference to specific hypotheses.

Figure 1 shows the impact of UA and COL on DPB and FPB.

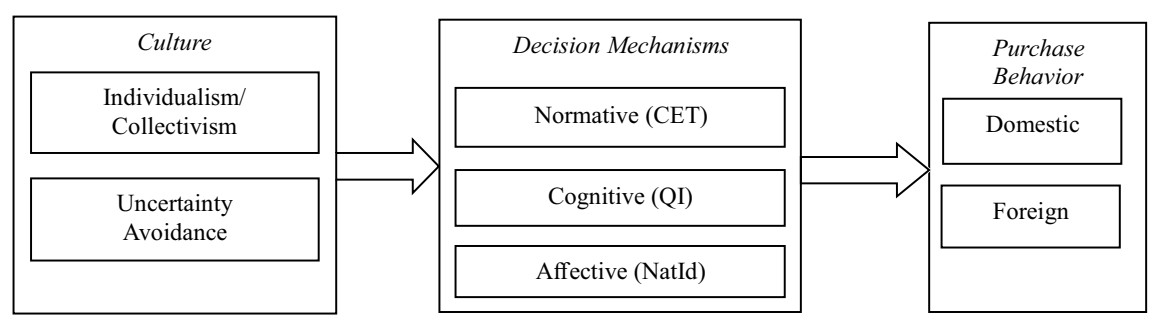

Fig. 1. Conceptual model

\section{Method}

\subsection{Sample}

This research examines a robust theoretical model independent of country context, consumer differences and product/industry types. To satisfy recommendations of Cadogan (2010) and Douglas and Craig (2006), we test this model in 19 nations - emerging, developing, and traditional economies. The sample was obtained by disaggregating the population and sampling each sub-population - conceptually similar to stratified sampling - although disproportionate and non-probability based. To obtain a relatively representative global sample, the authors purposefully chose areas of diverse culture, language, and economic development (see Appendix 1). The sample consisted of 5086 college students, chosen based on their relatively homogeneous extraneous influences, moderately high exposure to global commerce, and comparatively high exposure to multiple languages/cultures. 


\subsection{Measures}

The instrument was translated for both literal and symbolic meaning following Douglas and Craig (2006). The English version was used in the U.S., UK, Philippines, and India. All scale items were measured on 7 -point Likert-type scales $(1=$ strongly disagree, $7=$ strongly agree). Construct measures were derived from existing literature (NatID from Keillor et al. 1996; CET from Shimp and Sharma 1987; DPB from Granzin and Olsen 1998 and FPB from Suh and Kwon 2002). QI was adapted from consumer sentiment research (Gaski, Etzel 1986) while the measures of UA and COL were adopted from Quintal et al. (2006). Scale reliability was established using composite reliability with values being "respectable or better", i.e. higher than 0.70 (DeVellis 2003). Scale validity was tested with confirmatory factor analysis (CFA) (Joreskog, Sorbom 1993). Due to model complexity, CFAs for cultural variables and for the ethnocentric model variables were computed. The fit of both was good (RMSEA 0.56, GFI 0.98 and RMSEA 0.64, GFI 0.94, respectively). Convergent validity was tested by examining the t-values of the Lambda-X Matrix (Bagozzi 1981). Ranging from 43.3 to 90.19, all t-values were well above the 2.00 level, as specified by Kumar et al. (1992), indicating high convergent validity. In addition, the average variance extracted (AVE) exceeded 0.50 for all constructs (Fornell, Larcker 1981). Discriminant validity was examined by setting the individual paths of the phi matrix to one and testing the resultant model against the original (Gerbing, Anderson 1988). The high D-squared statistics (Joreskog, Sorbom 1993) implied the confirmatory factor model fit significantly better than the constrained model for each construct. The AVE exceeded the shared variance between constructs, the highest being 0.3721 (Fornell, Larcker 1981). A SEM model was estimated using LISREL.

\section{Results}

Figure 2 depicts the estimation and t-test results. The overall fit of the model is acceptable $($ AGFI $=0.91)$. As expected given the sample size, the chi-squared statistic is large and significant $(\chi 2=7147.63, \mathrm{P}=0.0)$.

The model describes the data well within acceptable limits. The RMSEA was below the 0.08 cutoff values of Browne and Cudeck (1992). The GFI and CFI are both above the recommended 0.90 limit (see Lichtenstein et al. 1992). The less sample-size dependent measures (e.g., NNFI) show adequate fit. Hypotheses are tested by examining the individual structural paths of the model (Appendix 2).

The adapted model fits the data well with a few notable exceptions. Interestingly, no significant relationship between CET and FPB was uncovered when DPB is simultaneously integrated into the model. In addition, there is relatively weak evidence of a link between QI and DPB. A p-value of 0.051, while obviously very close to the traditional alpha cut off, seems tenuous given the sample size and heterogeneity of this sample. Both of these paths become sizable and significant if estimated in isolation. This may suggest that previous research identified these linkages due to model under-specification or geographic-specific results. 


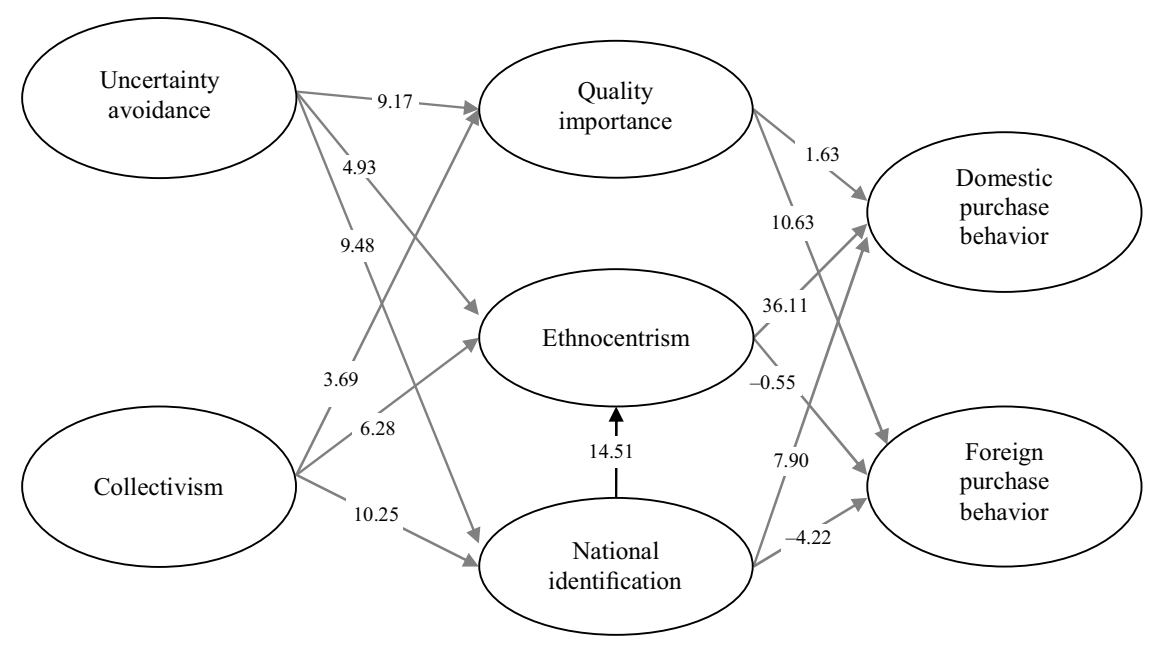

Fig. 2. Pooled model results $-\mathrm{t}$-values

All hypotheses were supported except $\mathrm{H} 2 \mathrm{~b}$ and $\mathrm{H} 3 \mathrm{~b}$. We suggested that collectivists would depend less on QI because of their inclination to depend more on other aspects (H2a and H2b). Apparently, collectivists tend to be more quality oriented, more ethnocentric, and have greater NatID than individualists. Thus, there seems to not be a tradeoff effect; using one mechanism does not lead to using less of another. This is also true for high UA consumers. The relative effects of UA on the decision mechanisms were also estimated from constrained models (Appendix 2).

\section{Conclusions}

This study provides support for an expanded model combining CAN and cultural elements to predict actual FPB and DPB. The findings suggest that both COL and UA directly and positively affect CAN elements. However, not all CAN elements have a direct effect on FPB and DPB. Our findings support the idea that normative and affective factors would have a greater effect on DPB than FPB.

The definition of CET suggests that consumers may believe that it is not appropriate, and possibly even immoral, to buy products from other countries because it costs domestic jobs and hurts the economy. The current results, drawn from over 5000 respondents, do not support this contention. While ethnocentric behaviour does encourage the purchase of domestic products, its effect on purchases of foreign goods was insignificant. While this finding is not unique, this discovery with good statistical power at such a global level, suggests that it may be time to re-examine the concept of CET as a phenomena that affects DPB rather than FPB.

Alternatively, it was hypothesized and support found for the contention that cognitive mechanisms affect FPB more than DPB. Consistent with extant literature, these findings suggest that consumers do not perceive decisions about buying domestic products and 
foreign products in the same manner; the decisions tend to be considered as separate selection sets and not as a large pool of products. This perception is important to consider for a multinational as it infers that competition is mostly against others of its ilk.

We hypothesised that collectivists will be more normative oriented and our findings support the literature that normative influences are predominant for collectivists, but they tend to first rely on group affect (NatId) followed by normative issues (CET). Further, the relative effects of UA on the decision mechanisms were also estimated and it appears that high UA consumers tend to be more nationalistic than ethnocentric and heavily quality oriented.

These findings have important implications for businesses that operate across borders. Ethnocentrism and national identity can be utilized as strategic segmentation and brand positioning variables. Positioning of domestic products/brands should focus on symbols that relate to ethnocentric tendencies. For instance, local products could benefit from focusing on national associations/symbols or "locally-made" aspects in their positioning strategies. It would also help retailers make strategic decisions regarding the assortment of domestic products in their retail outlets. Alternatively, quality oriented consumers tend toward more foreign purchases. Thus, it would follow that foreign goods need to concentrate on value aspects such as quality.

Furthermore, both collectivism and uncertainty avoidance directly and positively affect normative, cognitive, and affective elements. While "globalness" of consumers has been acknowledged, this study supports previous studies on divergent consumer behavior and suggests that differences need to be considered across cultures when expanding internationally. Hence, marketing efforts should differ with regard to cultural dimensions differentially for local or foreign products. Accordingly, positioning strategies could focus on risk reduction for high uncertainty avoidance societies by emphasizing social acceptance or accentuating group belonging for domestic products/brands. Alternatively, for foreign products in individualistic countries, value/quality positioning seems ideal, perhaps combined with a focus on personal values, personal achievements, individual success, or initiative.

A relatively parsimonious model was tested to examine CAN mechanisms underlying foreign and domestic purchase decisions. As such, the examination was limited to a single, latent construct as a representation of each mechanism. The literature suggests that the model may be richer than herein specified. Therefore, including other variables, such as animosity, cosmopolitanism or patriotism, may provide wealthier results for future studies.

While the current study used actual purchase behaviour, further studies could test the differences between actual behaviour and intentions. Also, use of a student sample restricted predictions to that demographic segment. Future research should endeavour to sample multiple age segments to check if factors such as NatID and COO are held as strongly across the entire population.

Because of the scope of the paper, our study was limited to surveying COO effects on actual purchase behaviour, but future research could attempt to study the link between 
cognitive or affective processes and COO effects when breaking down COO into country of design and country of parts and country of manufacturing.

The current study examined the relative order of the effects without considering the role of economic development of a country. Thus, future research could consider testing the model among developing nations and emerging economies where consumers tend to be less confident of locally produced products. An unexplored aspect of this continuum is how sharp the distinction is between developing and emerging markets. Given the growing importance of these countries, implications for government policies on economic development and multinational competitor strategies may be explored.

\section{References}

Ahmed, S. A.; d'Astous, A. 2007. Moderating effect of nationality on country-of-origin perceptions: English-speaking Thailand versus French-speaking Canada, Journal of Business Research 60: 240-248. https://doi.org/10.1016/j.jbusres.2006.11.004

Ahmed, S. A.; d'Astous, A. 2008. Antecedents, moderators and dimensions of country-of-origin evaluations, International Marketing Review 25(1): 75-106.

https://doi.org/10.1108/02651330810851890

Al-Aali, A.; Randheer, K.; Hasin, S. 2015. Do the subcomponents of country of origin trigger purchase intentions?, International Journal of Commerce \& Management 25(4): 627-640.

https://doi.org/10.1108/IJCoMA-05-2013-0047

Arora, A. S.; Wu, J.; Arora, A.; Bacouel-Jentjens, S.; McIntyre, J. 2016. Miu Miu diffuses Prada: coupling country-of-origin versus country-of-manufacture effects with brand authenticity and contagion, Journal of International Consumer Marketing 28(4): 228-250.

https://doi.org/10.1080/08961530.2016.1148655

Ajzen, I. 2001. Nature and operation of attitudes, Annual Review of Psychology 52(1): 27-58. https://doi.org/10.1146/annurev.psych.52.1.27

Bagozzi, R. P. 1981. Evaluating structural equation models with unobservable variables and measurement error: a comment, Journal of Marketing Research 18: 375-381.

https://doi.org/10.2307/3150979

Balabanis, G.; Diamantopoulos, A. 2004. Domestic country bias, country-of-origin effects and consumer ethnocentrism: a multidimensional unfolding approach, Journal of the Academy of Marketing Science 32(1): 80-95. https://doi.org/10.1177/0092070303257644

Balabanis, G.; Diamantopoulos, A.; Mueller, R. D.; Melewar, T. C. 2001. The impact of nationalism, patriotism and internationalism on consumer ethnocentric tendencies, Journal of International Business Studies 32(1): 157-175.

https://doi.org/10.1057/palgrave.jibs. 8490943

Bertini, M.; Wathieu, L.; Iyengar, S. S. 2012. The discriminating consumer: product proliferation and willingness to pay for quality, Journal of Marketing Research 49(1): 39-49.

https://doi.org/10.1509/jmr.10.0028

Broderick, A. J. 2007. A cross-national study of the individual and national - cultural nomological network of consumer involvement, Psychology and Marketing 24(4): 343-374.

https://doi.org/10.1002/mar.20164

Browne, M. W.; Cudeck, R. 1992. Alternative ways of assessing model fit, Sociological Methods Research 21(2): 230-258. https://doi.org/10.1177/0049124192021002005 
Cadogan, J. 2010. Comparative, cross-cultural and cross-national research: a comment on good and bad practice, International Marketing Review 27(6): 601-605.

https://doi.org/10.1108/02651331011088245

Chen, L. 2013. A study of green purchase intention comparing with collectivistic (Chinese) and individualistic (American) consumers in Shanghai, China, Information Management and Business Review 5(7): 342-346.

Chen, C. Y.; Mathur, P.; Maheswaran, D. 2014. The effects of country-related affect on product evaluations, Journal of Consumer Research 41: 1033-1046.

https://doi.org/10.1086/678194

Cleveland, M.; Laroche, M. 2007. Acculturation to the global consumer culture: scale development and research paradigm, Journal of Business Research 60(3): 249-259.

https://doi.org/10.1016/j.jbusres.2006.11.006

Dacin, P. A.; Smith, D. C. 1994. The effect of brand portfolio characteristics on consumer evaluations of brand extensions, Journal of Marketing Research 31(2): 229-242.

https://doi.org/10.2307/3152196

De Matos, C. A.; Von der Heyde, F. D.; Pinto, L. R.; Trez, G. 2011. A cross-cultural investigation of customer reactions to service failure and recovery, Journal of International Consumer Marketing 23(3-4): 211-228.

DeVellis, R. 2003. Scale development. Thousand Oaks: Sage Publications.

Douglas, S. P.; Craig, C. S. 2006. On improving the conceptual foundations of international marketing research, Journal of International Marketing 14(1): 1-22.

https://doi.org/10.1509/jimk.14.1.1

Druckman, D. 1994. Nationalism, patriotism, and group loyalty: a social psychological perspective, Mershon International Studies Review 38(1): 43-68.

https://doi.org/10.2307/222610

Fishbein, M.; Middlestadt, S. 1995. Noncognitive effects on attitude formation and change: fact or artifact?, Journal of Consumer Psychology 4(2): 181-202.

https://doi.org/10.1207/s15327663jcp0402_05

Fornell, C.; Larcker, D. F. 1981. Evaluating structural equation models with unobservable variables and measurement error, Journal of Marketing Research 18(3): 39-50.

https://doi.org/10.2307/3151312

Franke, G. R.; Nadler, S. S. 2008. Culture, economic development and national ethical attitudes, Journal of Business Research 61(3): 254-264. https://doi.org/10.1016/j.jbusres.2007.06.005

Gaski, J. F.; Etzel, M. J. 1986. The index of consumer sentiment toward marketing, Journal of Marketing 50(3): 71-81. https://doi.org/10.2307/1251586

Gerbing, D. W.; Anderson J. C. 1988. An updated paradigm for scale development incorporating unidimensionality and its assessment, Journal of Marketing Research 25(2): 186-92.

https://doi.org/10.2307/3172650

Granzin, K. L.; Olsen, J. E. 1998. Americans' choice of domestic over foreign products: a matter of helping behavior?, Journal of Business Research 43(1): 39-54.

https://doi.org/10.1016/S0148-2963(97)00101-X

Guo, X. 2013. Living in a global world: influence of consumer global orientation on attitudes toward global brands from developed versus emerging countries, Journal of International Marketing 21(1): 1-22. https://doi.org/10.1509/jim.12.0065

Hofstede, G. 2001. Culture's consequences: comparing values, behaviors, institutions and organizations across nations. Thousand Oaks: Sage Publications.

Johansson, J. 2009. Global marketing. 5 ed. Boston: McGraw-Hill/Irwin. 
Joreskog, K.; Sorbom, D. 1993. LISREL 8: Structural equation modelling with the SIMPLIS command language. Chicago, IL: Scientific Software.

Josiassen, A.; Harzing, A. W. 2008. Comment: descending from the ivory tower: reflections on the relevance and future of country-of-origin research, European Management Review 5(4): 264-270. https://doi.org/10.1057/emr.2008.19

Keillor, B. D.; Hult, G. T.; Erffmeyer, R. C.; Babakus, E. 1996. NATID: The development and application of a national identity measure for use in international marketing, Journal of International Marketing 4(2): 57-73.

Klein, J. G.; Ettenson, R.; Krishnan, B. C. 2006. Extending the construct of consumer ethnocentrism: when foreign products are preferred, International Marketing Review 23(3): 304-312. https://doi.org/10.1108/02651330610670460

Koubaa, Y.; Methamem, R. B. 2015. Multidimensional structures of brand and country images, and their effects on product evaluation, International Journal of Market Research 57(1): 95-124. https://doi.org/10.2501/IJMR-2015-007

Kumar, N.; Stern, L. W.; Achrol, R. S. 1992. Assessing reseller performance from the perspective of the supplier, Journal of Marketing Research 29(2): 238-253. https://doi.org/10.2307/3172573

Lam, S. K.; Ahearne, M.; Schillewaert, N. 2012. A multinational examination of the symbolicinstrumental framework of consumer-brand identification, Journal of International Business Studies 43: 306-331. https://doi.org/10.1057/jibs.2011.54

Lee, J. A.; Garbarino, E.; Lerman, D. 2007. How cultural differences in uncertainty avoidance affect product perceptions, International Marketing Review 24(3): 330-349.

https://doi.org/10.1108/02651330710755320

Lee, J. A.; Kacen, J. J. 2008. Cultural influences on consumer satisfaction with impulse and planned behavior, Journal of Business Research 61(3): 265-272.

https://doi.org/10.1016/j.jbusres.2007.06.006

Lichtenstein, D. R.; Ridgway, N. M.; Netemeyer, R. G. 1992. Price perceptions and consumer shopping behavior: a field study, Journal of Marketing Research 30(2): 234-245.

https://doi.org/10.2307/3172830

Mockaitis, A. I.; Salciuviene, L.; Ghauri, P. Z. 2013. On what do consumer product preferences depend? Determining domestic versus foreign product preferences in an emerging economy market, Journal of International Consumer Marketing 25(3): 166-180.

https://doi.org/10.1080/08961530.2013.780456

Mourali, M.; Laroche, M.; Pons, F. 2005. Individualistic orientation and consumer susceptibility to interpersonal influence, Journal of Services Marketing 19(3):164-173.

https://doi.org/10.1108/08876040510596849

Nakos, G. E.; Hajidimitriou, Y. A. 2007. The impact of national animosity on consumer purchases: the modifying factor of personal characteristics, Journal of International Consumer Marketing 19(3): 53-72. https://doi.org/10.1300/J046v19n03_04

Nes, E. B.; Yelkur, R.; Silkoset, R. 2014. Consumer affinity for foreign countries: construct development, buying behaviour consequences and animosity contrasts, International Business Review 23(4): 774-784. https://doi:10.1016/j.ibusrev.2013.11.009

Oyserman, D.; Lee, S. W. S. 2008. Does culture influence what and how we think? Effects of priming individualism and collectivism, Psychological Bulletin 134(2): 311-342.

https://doi.org/10.1037/0033-2909.134.2.311

Petty, R. E.; Cacioppo, J. T.; Schumann D. 1983. Central and peripheral routes to advertising effectiveness: the moderating role of involvement, Journal of Consumer Research 10(2): 135-146. https://doi.org/10.1086/208954 
Quintal, V.; Lee, J.; Soutar, G. 2006. Attitudes towards risk and uncertainty: suggested scales, in Proceedings of the Australian and New Zealand Marketing Academy, 4-6 December 2006, Brisbane, Australia.

Roth, K. P.; Diamantopoulos, A. 2009. Advancing the country image construct, Journal of Business Research 62(7): 726-740. https://doi.org/10.1016/j.jbusres.2008.05.014

Shankarmahesh, M. N. 2006. Consumer ethnocentrism: an integrative review of its antecedents and consequences, International Marketing Review 23(2): 26-37.

https://doi.org/10.1108/02651330610660065

Sharma, S.; Shimp, T. A.; Shin, J. 1995. Consumer ethnocentrism: a test of antecedents and moderators, Journal of the Academy of Marketing Science 23(1): 26-37.

https://doi.org/10.1007/BF02894609

Shimp, T. A.; Sharma, S. 1987. Consumer ethnocentrism: construction and validation of the CETSCALE, Journal of Marketing Research 24(3): 280-289.

https://doi.org/10.2307/3151638

Soares, A. M.; Farhangmehr, M.; Shoham, A. 2007. Hofstede's dimensions of culture in international marketing studies, Journal of Business Research 60(3): 277-284.

https://doi.org/10.1016/j.jbusres.2006.10.018

Suh, T.; Kwon, I. W. G. 2002. Globalization and reluctant buyers, International Marketing Review 19(6): 663-680. https://doi.org/10.1108/02651330210451962

Triandis, H. 1995. Individualism and collectivism. Boulder: Westview Press.

Tsai, W. S.; Yoo, J. J.; Lee, W. 2013. For love of country? Consumer ethnocentrism in China, South Korea, and the United States, Journal of Global Marketing, 26(2): 98-114.

https://doi.org/10.1080/08911762.2013.805860

Verlegh, P. W. J. 2007. Home country bias in product evaluation: the complementary roles of economic and socio-psychological motives, Journal of International Business Studies 38(3): 361-373. https://doi.org/10.1057/palgrave.jibs.8400269

Verlegh, P. W. J.; Steenkamp, J. B. E. M. 1999. A review and meta-analysis of country-of-origin research, Journal of Economic Psychology 20(5): 521-546.

https://doi.org/10.1016/S0167-4870(99)00023-9

Vida, I.; Reardon, J. 2008. Domestic consumption: rational, affective or normative choice?, Journal of Consumer Marketing 25(1): 34-44.

https://doi.org/10.1108/07363760810845390

Yoo, B.; Donthu, N. 2005. The effect of personal cultural orientation on consumer ethnocentrism, Journal of International Consumer Marketing 18(1-2): 7-44.

https://doi.org/10.1300/J046v18n01_02 


\section{APPENDIX 1}

\section{Sample country description}

\begin{tabular}{|c|c|c|c|}
\hline \multirow{2}{*}{ Country } & \multirow{2}{*}{$\mathrm{N}$} & \multicolumn{2}{|c|}{ Hofstede's Measures } \\
\hline & & $\mathrm{COL}$ & UA \\
\hline \multicolumn{4}{|c|}{$E U R O P E$} \\
\hline Belgium (BEL) & 250 & 75 & 94 \\
\hline Croatia (CRO) & 207 & & \\
\hline Finland (FIN) & 223 & 63 & 59 \\
\hline France (FRA) & 329 & 71 & 86 \\
\hline Italy (ITA) & 409 & 76 & 75 \\
\hline Latvia (LAT) & 123 & & \\
\hline Lithuania (LIT) & 196 & & \\
\hline Portugal (POR) & 291 & 27 & 104 \\
\hline Russia (RUS) & 335 & 39 & 95 \\
\hline Serbia (SER) & 254 & & \\
\hline Slovenia (SLO) & 291 & & \\
\hline United Kingdom (UK) & 204 & 89 & 35 \\
\hline \multicolumn{4}{|c|}{ AMERICAS } \\
\hline Guatemala (GUA) & 241 & 6 & 101 \\
\hline United States (US) & 446 & 91 & 46 \\
\hline \multicolumn{4}{|l|}{ ASIA } \\
\hline China (PRC) & 207 & 20 & 30 \\
\hline India (IND) & 193 & 48 & 40 \\
\hline Japan (JAP) & 285 & 46 & 92 \\
\hline Philippines (PHI) & 379 & 32 & 44 \\
\hline Turkey (TUR) & 222 & 37 & 85 \\
\hline \multicolumn{4}{|c|}{ OTHER } \\
\hline $\begin{array}{l}\text { Exchange students mostly from } \\
\text { Ukraine and the Netherlands }\end{array}$ & 8 & & \\
\hline Totals Range & 5086 & $20-91$ & $30-104$ \\
\hline
\end{tabular}


S. L. Conner et al. Cultural antecedents to the normative, affective, and cognitive effects of domestic versus ...

\section{APPENDIX 2}

Model and hypotheses results

\begin{tabular}{|c|c|c|c|c|}
\hline Base Mc & el Confirmation & Estimate & t/p-value & \\
\hline \multicolumn{2}{|c|}{$\mathrm{CET} \rightarrow \mathrm{DPB}(+)$} & +0.59 & $36.11 / \mathrm{p}<0.001$ & As expected \\
\hline \multicolumn{2}{|c|}{$\mathrm{CET} \rightarrow \mathrm{FPB}(-)$} & -0.01 & $0.055 / \mathrm{p}=0.582$ & Not significant \\
\hline \multicolumn{2}{|c|}{$\mathrm{QI} \rightarrow \mathrm{DPB}(+)$} & +0.02 & $1.63 / \mathrm{p}=0.051$ & Marginal \\
\hline \multicolumn{2}{|c|}{$\mathrm{QI} \rightarrow \mathrm{FPB}(+)$} & +0.17 & $10.63 / \mathrm{p}<0.001$ & As expected \\
\hline \multicolumn{2}{|c|}{ NatID $\rightarrow$ CET $(+)$} & +0.21 & $14.51 / \mathrm{p}<0.001$ & As expected \\
\hline \multicolumn{2}{|c|}{ NatID $\rightarrow$ DPB $(+)$} & +0.10 & $7.90 / \mathrm{p}<0.001$ & As expected \\
\hline \multicolumn{2}{|c|}{ NatID $\rightarrow$ FPB $(-)$} & -0.06 & $4.22 / \mathrm{p}<0.001$ & As expected \\
\hline Hypotheses & Linkage & Estimate & t/p-value & Results \\
\hline $\mathrm{H}^{2} \mathrm{a}^{1}$ & $\begin{array}{c}|\{\mathrm{CET} \rightarrow \mathrm{DPB}\}|> \\
|\{\mathrm{CET} \rightarrow \mathrm{FPB}\}|\end{array}$ & $\begin{array}{c}\text { D-Squared } \\
1060.26\end{array}$ & $\mathrm{p}<0.001$ & Supported \\
\hline $\mathrm{H} 1 \mathrm{~b}$ & $\begin{array}{l}\{\mathrm{QI} \rightarrow \mathrm{DPB}\}< \\
\{\mathrm{QI} \rightarrow \mathrm{FPB}\}\end{array}$ & $\begin{array}{c}\text { D-Squared } \\
44.79\end{array}$ & $\mathrm{p}<0.001$ & Supported \\
\hline $\mathrm{H} 1 \mathrm{c}^{1}$ & $\begin{array}{c}|\{\mathrm{NatID} \rightarrow \mathrm{DPB}\}|> \\
|\{\mathrm{NatID} \rightarrow \mathrm{FPB}\}|\end{array}$ & $\begin{array}{c}\text { D-Squared } \\
13.96\end{array}$ & $\mathrm{p}<0.001$ & Supported \\
\hline $\mathrm{H} 2 \mathrm{a}$ & $\mathrm{COL} \rightarrow \mathrm{CET}(+)$ & +0.10 & $6.28 / \mathrm{p}<0.001$ & Supported \\
\hline $\mathrm{H} 2 \mathrm{~b}$ & $\mathrm{COL} \rightarrow \mathrm{QI}(-)$ & +0.06 & $3.69 / \mathrm{p}<0.001$ & $\begin{array}{c}\text { Rejected } \\
\text { Opposite direction }\end{array}$ \\
\hline $\mathrm{H} 2 \mathrm{c}$ & $\mathrm{COL} \rightarrow \mathrm{NatID}(+)$ & +0.15 & $10.25 / \mathrm{p}<0.001$ & Supported \\
\hline $\mathrm{H} 3 \mathrm{a}$ & $\mathrm{H} 2 \mathrm{c}>\mathrm{H} 2 \mathrm{~b}$ & $\begin{array}{c}\text { D-Squared } \\
16.03\end{array}$ & $\mathrm{p}<0.001$ & Supported \\
\hline $\mathrm{H} 3 \mathrm{~b}$ & $\mathrm{H} 2 \mathrm{a}>\mathrm{H} 2 \mathrm{c}$ & $\begin{array}{l}\text { D-Squared } \\
4.20\end{array}$ & $\mathrm{p}=0.040$ & $\begin{array}{c}\text { Rejected } \\
\text { Opposite direction }\end{array}$ \\
\hline $\mathrm{H} 4 \mathrm{a}$ & $\mathrm{UA} \rightarrow \mathrm{CET}(+)$ & +0.08 & $4.93 / \mathrm{p}<0.001$ & Supported \\
\hline $\mathrm{H} 4 \mathrm{~b}$ & $\mathrm{UA} \rightarrow \mathrm{QI}(+)$ & +0.015 & $9.17 / \mathrm{p}<0.001$ & Supported \\
\hline $\mathrm{H} 4 \mathrm{c}$ & $\mathrm{UA} \rightarrow \mathrm{NatID}(+)$ & +0.14 & $9.48 / \mathrm{p}<0.001$ & Supported \\
\hline post hoc & $\mathrm{H} 4 \mathrm{a}<\mathrm{H} 4 \mathrm{~b}$ & $\begin{array}{c}\text { D-Squared } \\
35.76\end{array}$ & & 0.001 \\
\hline post hoc & $\mathrm{H} 4 \mathrm{~b}<\mathrm{H} 4 \mathrm{c}$ & $\begin{array}{c}\text { D-Squared } \\
32.74\end{array}$ & & 0.001 \\
\hline
\end{tabular}

Note: ${ }^{1}$ Models constrained to paths to be equal in absolute value in H1a and H1c. 
Suzanne L. CONNER is an Assistant Professor of Marketing at Georgia Southwestern State University. She received her PhD in 2012 from New Mexico State University. Her research focuses on consumer behavior, sustainability practice and systems, green marketing, and ethics. She is an editorial review board member of Journal of Global Marketing and Journal of Digital \& Social Media Marketing.

James REARDON is the Chairperson and Professor of Marketing at the Monfort College of Business. His publications have appeared in the Journal of Marketing, Journal of Retailing, Journal of International Marketing, Journal of Marketing Education, among others. He was named the UNC Distinguished Scholar and has been named the Monfort College Scholar five times. In addition, he has been named marketing professor of the year three times. His non-academic background includes managing several businesses in various functions in the Home Shopping, Construction, Casino, and Film industries.

Chip MILLER has a PhD in marketing from the University of Washington. He has published in a wide range of journals including Journal of Marketing, Journal of International Marketing, International Marketing Review and European Journal of Marketing. His current research interests lie in international consumer behavior, Asian marketing practice as it relates to economic and brand development, and marketing management. He has received awards for both teaching and research during his career.

Laura SALCIUVIENE is a lecturer in Marketing at Lancaster University Management School in the UK. Previously she worked at Manchester Business School. Her research focuses on how consumer attitudes are formed in online retailing and cross-cultural environments. She has had articles published in international journals, including Advances in Consumer Research, Journal of Marketing Management and International Business Review. She has acted as guest editor for two special issues of the Journal of Consumer Behaviour and Journal of Virtual Worlds Research.

Vilte AURUSKEVICIENE is Professor and Vice-President for studies at ISM University of Management and Economics in Lithuania. Her research is multidisciplinary and focuses on cross-cultural behavioural issues in real and virtual environments. She has participated in a number of international and national research and development projects. The most resent project "Functional food: drivers and repulses of consumers' preferences choices" is granted by the Research Council of Lithuania using bilateral research funding scheme of Lithuanian and Japanese government. She is an editorial board member of Baltic Journal of Management and International Director of Eastern Europe Marketing Educators' Association. 